\title{
Retail location preferences: A comparative analysis
}

Oluwole Adeniyi*1 Paul Whysall ${ }^{1}$, Abraham Brown ${ }^{1}$

Nottingham Trent University, United Kingdom

\begin{abstract}
There is widespread criticism that gambling retailers are concentrated in deprived communities and that the concentration is deliberately targeted. However, this study opines that before deliberate targeting can be supported, a comparative analysis of gambling locations with a more conventional retail group is necessary. Hence this study examined the location preferences of gambling and food and grocery retailers (FGRs) to evaluate the notion of deliberate concentration of gambling retailers in deprived communities. Comparative analyses assessed relationships between FGRs floorspaces and overall gambling locations compared to socio-economic deprivation. Results showed similarities and disparities in retail locations, but gambling provisioning were more concentrated in deprived areas compared to food provisioning. Implications for policy and practice are presented.
\end{abstract}

Keyword - Socio-economic deprivation, gambling, food and grocery retailers, location preference, binary logistic regression, geographical information systems

\section{Declaration of interest: None}

Funding: This research received no specific funding from any funding agency in the public, commercial or not-for-profit sectors.

Acknowledgement: The authors acknowledge members of the $\mathrm{PhD}$ monitoring team at the Nottingham Trent University for their constructive feedback. Special thanks to members of

\footnotetext{
* Corresponding author: oluwoleadeniyi2015@my.ntu.ac.uk

${ }^{1}$ Present address: Marketing Department, Nottingham Trent Business School, Nottingham Trent University. NG1 4BU.
} 
British Academy of Management and Geographical Information Science UK for their feedback and comments. 


\subsection{Introduction}

Policy makers and scholars in retail and deprivation studies have become more interested in the immediate environment and current retail structures, because improving the retail characteristics of communities can serve as a panacea for improving these communities. Such studies have found strong linkages between retailing and areas of socio-economic deprivation (Cummins and Macintyre, 2002; Block et al., 2004; Wardle et al., 2014). Notably, these areas have high proportions of people with less education, lower or routine employment, low income and individuals who are benefit dependent. Research suggests that deprived communities are typified by largely unfavourable business structures with proportionally more gambling outlets, high yield interest lenders, bingo halls, fast food outlets and generally low order retail outlets (Townshend, 2017). Patronage of these retailers has been linked to unhealthy behaviours such as obesity (Bodicoat et al., 2015), problem gambling (Abbot et al., 2004), and other deviant behaviours (Kubrin et al., 2011).

Evidence regarding the prevalence of gambling outlets and food and grocery retailers (FGRs) in deprived communities is mixed. For instance, in the US, some studies suggest that there is a systematic absence of supermarket and multiple retailers in inner cities and the most deprived areas (Zenk et al., 2005; Gordon et al., 2011), while other studies found a prevalence of supermarkets, multiples and independents in deprived areas (Sharkey and Horel, 2008). Likewise, in Canada, there is also mixed evidence as regards the relationship between food and grocery retailers (FGR) locations and socio-economic deprivation. For example, Gould et al. (2012) and Smoyer-Tomic et al. (2006) discovered abundant provision of food retailers in low income households and inner-city neighbourhoods. However, similar studies (Larson and Gilliland, 2008; Black et al., 2011) found the worst access was in the most deprived areas. In the UK, similar patterns 
of inadequate provisioning are observed in terms of variety (Burgoine et al., 2017) and price (Wrigley, 2002). Nonetheless, other studies suggest that food and supermarket provisioning mostly favour deprived areas (Cummins and Macintyre, 2002; Smith et al., 2009).

In the gambling sector, there is a substantial empirical body of evidence which strongly suggests a high prevalence of gambling opportunities in deprived communities. International studies found concentrations of gambling machines in deprived communities (Wheeler et al., 2006; Young et al., 2009). In the UK, the prevalence of gambling has been explored by examining the distribution of both fixed odds betting terminals (FOBTs) and betting shops (Wardle et al., 2014). The authors discovered a prevalence of FOBTs in deprived neighbourhoods and seaside towns, while Whysall (2014) carried out a comparative analysis which revealed that betting shops are not more prone to being in deprived areas when compared to many other retailers.

From the above, there is the possibility that retailers' (gambling and food retailers) location preferences are skewed towards poor areas. Interestingly, some scholars and critics of the gambling sector attribute their concentration in deprived and underprivileged areas as a deliberate attempt to target inhabitants of these communities because of their hard-pressed characteristics (Portas, 2011; Pidd, 2017). This notion has received widespread approval because of the controversial nature of gambling services, especially because of several unethical practices involving violating regulations to the customers' detriment (BBC, 2018; Gambling Commission, 2018).

Research in the UK has shown that deprived areas are high density machine zones (Wardle et al., 2014). These fixed odds betting terminals (FOBTs), have been dubbed 
"the crack cocaine of gambling" (Dowling et al., 2004) because of their links to pathological gambling. However, less is known about whether gambling retailers are deliberately targeting these communities. On the other hand, since empirical research shows that there is concentration of food retailers (supermarkets, multiples and independents) in deprived areas, then it may be inaccurate to infer that gambling retailers are deliberately targeting poor communities without adequate empirical support.

Therefore, before the "deliberate targeting motive" of deprived areas ascribed to gambling retailers can be accurately inferred, their location preferences need to be critically compared with those of a more conventional retail group. Undoubtedly, only this comparative analysis will offer in-depth understanding of the location preference of gambling retailers. Therefore, this study aims to examine the relationship between gambling outlets, FGRs floorspaces and socio-economic deprivation (SED). Unlike most studies, this paper seeks to compare the location preferences of gambling outlets, FGRs floorspaces and outlets to SED in order to uncover disparities related to the presence and absence of both retailers in deprived communities. This study uses multiple methods hotspot analysis, correlation, ANOVA, and binary logistic regression - to offer a countrywide, quantitative comparative assessment of location disparities of gambling outlets and FGRs.

\subsection{Literature Review}

\subsection{Food Retailers}

The food landscape has attracted attention because of dietary implications, which has consequently generated a series of debates about food availability. The geography of supermarket and food multiples is somewhat conflicting, creating widespread arguments. For example, in Australia, there is strong evidence of concentration of FGRs in deprived 
and low-income areas (Burns and Inglis, 2007). Likewise, in Canada, Smoyer-Tomic et al. (2006), Black et al. (2011), and Gould et al. (2012) discovered best access to supermarkets in inner city and deprived communities. The studies also found worst provisioning in pockets of deprived areas. Nonetheless, these Canadian studies concluded that to a large extent, deprived areas have abundant presence of FGRs.

In the US, there is conflicting evidence on the spatial distribution of food retailers with evidence supporting poor provisioning in deprived areas (Zenk et al., 2005; Gordon et al., 2011), while other scholars have found that deprived neighbourhoods and inner cities have better access to supermarket and food multiples (Sharkey and Horel, 2008). The evidence in the UK corroborates findings of similar studies in Canada and Australia, with concentration and ample provisioning of grocers in deprived areas (Cummins and Macintyre, 2002; Black et al., 2012). In contrast to the previous findings, a recent study in the UK found education deprived communities travel longer distances to supermarkets (Burgoine et al., 2017).

To explain the forces at play in the observed food retail location patterns, Black et al. (2011) further explored if zoning and urban land use systems exert important influence on the existing patterns of FGRs and concluded that the prevailing zoning regulation explains distribution of retailers in deprived and affluent neighbourhoods. Likewise, Smoyer-Tomic et al. (2006) alluded that the spatial distribution of food retailers might be because of the economic development and centrality of inner-city neighbourhoods. This introduces a new dimension to explanations for the geography of FGRs, suggesting that not only do socio-economic characteristics influence supermarket locations, but the contextual explanation might also include the effect of zoning and urban regulations. 


\subsection{Gambling Retailers}

The prevalence of gambling opportunities has increased in recent times and the UK outlook has witnessed key mergers and acquisitions (Guardian, 2015). Participation in gambling has also increased due to its widespread acceptability. Demand for gambling stems from individuals with little or low education and low income, single parents and ethnic minorities (Wardle et al., 2010) and these characteristics are typically found in deprived neighbourhoods.

Hence, scholars and community stakeholders (Wheeler et al., 2006; Wardle et al., 2014; Portas, 2011) have raised several concerns about the operators' location expansion strategies. There have also been contentions about the location preferences of their fixed odds betting terminals (FOBTs). These FOBTs have been said to be largely concentrated in deprived and underprivileged communities. In Australia and New Zealand, there are widespread evidence suggesting the concentration of gaming machines in areas with low socio-economic characteristics (Wheeler et al., 2006; Young et al., 2009). Similar studies in Canada also suggest that gambling opportunities vary along a socio-economic classification, with low income areas having high concentrations (Gilliland and Ross, 2005; Robitaille and Herjean, 2008). Likewise, a UK study found evidence of concentrations of FOBTs in deprived areas (Wardle et al., 2014). As a result of the inherent risk associated with participation in gambling (Abbot et al., 2004), if the concentrations are targeted, they will further worsen the health outcomes in deprived areas.

Interestingly, scholars further suggest that the explanation for the spatial distribution of gambling opportunities in deprived areas is complex, and socio-economic characteristics do not adequately explain the observed patterns. Gilliland and Ross (2005) further 
showed that historical and prevailing alcohol licensing and urban zoning classification exerts strong influences on the observed distribution of machine availability. Likewise, in Australia, observed patterns of gambling results from an interplay of location dynamics, government rules and regulations, zoning structures, marketing strategies and area socioeconomic characteristics (Young et al., 2009). These clearly show that the patterns might not be solely a result of deliberate targeting as attributed by critics but, rather, an interplay of several micro-scale factors.

\subsection{Theoretical Framework}

Central Place (Christaller, 1966), Bid Rent (Haig, 1927) and principle of minimum differentiation (Hotelling, 1929) theories have generally been employed to explain the retail location process (Reigadinha et al., 2017). A major drawback of these classical theories is the assumption that all consumers are equal and uniform across the landscapes. Consumer demand is driven by consumer behaviour and varies across socio-economic dimensions (Foxall, 1990; Hoyer and Maclinnis, 2010). Furthermore, classical theories assume that businesses are merely responding to consumer demand. However, selection of retail location involves strategic planning, competitor analysis and, more importantly, government regulations (Ghosh and Craig, 1983). In addition, because retail location should offer consumers convenience (Reimers and Clulow, 2004) retailers further develop market strategies to inform optimum retail location choice. It is these choices that critics are particularly concerned with, and which have informed their arguments on deliberate concentration and targeting. In furtherance, classical theories fail to incorporate the dynamic nature of retail formation. For instance, the British retail landscape has evolved through stages (Schiller, 1971: 1988; Wood et al., 2006) which have strongly contributed to the present retail formation, regardless of the effect of area deprivation. 
Irrespective of the various limitations of traditional retail location theories, there are some salient lessons that may be applicable to the location preferences of gambling retailers. The extension of the principle of minimum differentiation theory (Weber, 1972) makes a valid argument for the clustering of businesses because it reduces the risk of uncertainty and allows for healthy competition. This notion was first introduced by Nelson (1954) which he termed cumulative attraction and explained that agglomeration of similar retailers offers numerous advantages which serves as strong attraction for businesses. These advantages serve as a pull factor for retailers (Pascal and McCall, 1980) and might explain the concentration of FGRs and gambling retailers in deprived areas, as observed in the literature review. The Bid Rent Theory emphasises the importance of centrality because of the advantages it offers to businesses (Haig, 1927). Therefore, agglomeration and the numerous attractions that these deprived centres offer might also hold explanation to the observed location preferences.

The spatial interaction model, on the other hand, offers a new dimension in retail location process by incorporating consumer behaviour and geo-demographics into location choices (Davies and Rogers, 1984; Nakaya et al., 2007), rather than assuming homogeneity of consumers. Consequently, explanation of retail location preferences requires careful analysis of the interplay between socio-economic characteristics in a local context. This informed the development of spatial interaction models which are mainly used to understand consumer behaviour. This introduces the location context and dynamism of each locality. Therefore, neighbourhood characteristics and other external factors contribute to the explanation for the prevalence of retail formations (Brown, 1992; Ghosh, 1994). 
Consequently, waves of decentralisation (which shape the general retail landscape), growth of online retail trade, PPG6 guidance legislation (Wood et al., 2006), neighbourhood characteristics and consumer behaviour might hold the explanation for observed patterns in the food sector. The above, as well as the Gaming Act (2005), which has regulated FOBTs but failed to restrict opening of new betting shops, might hold the explanation for the spatial distribution of gambling opportunities. In addition, the abundance of vacant premises (Department of Health, 1991; Whysall, 1995; Townshend, 2017) and cheap rent in deprived areas could have attracted gambling retailers. Rather, critics allege that, the concentration of gambling activities in deprived neighbourhood is, in fact, actively targeted.

Hence, this study assumes a very practical stance by adopting multiple analytic methods to allow for robust assessment of retail location disparities and examine the extent to which both retailers are concentrated in deprived areas.

\subsection{Data and Methods}

Socio-economic deprivation was measured using the indices of multiple deprivation data (IMD) for 2015 (Smith et al, 2015). This study adopted income, employment and education domains because international studies (Larson and Gilliland, 2008; Robitaille and Herjean 2008) suggest that these 3 aspects of deprivation might exert greatest influences on retail location preferences.

Gambling addresses were obtained from The Gambling Commission (April 2015 version) and it contained addresses of all gambling locations including casinos, family entertainment centres, bingo halls, amusement centres and bookmakers in the UK. For food provisioning, this study adopted the floorspace size of all supermarkets, food 
independents and multiples obtained from Geolytix (April 2016). The Geolytix dataset had 4 floorspace categories namely (a) $<3,013 \mathrm{ft}^{2}$, (b) 3,013 to $15,069 \mathrm{ft}^{2}$, (c) 15,069 to $30,138 \mathrm{ft}^{2}$ and (d) $30,138+\mathrm{ft}^{2}$. All floorspace categories were converted to count variables by averaging each of the categories. In addition, the addresses for both FGRs, gambling locations were also at postcode geography. Therefore, the measure for each retail group's provisioning (floorspaces and outlets for FGRs and outlets for gambling and casino outlets) were aggregated and geocoded to lower super output area (LSOA) geography using a look-up table provided by Geoconvert. Thereafter, these were weighted with the respective LSOAs populations (without converting each floorspace category into a count variable, it would be problematic to create weighted representations).

Altogether, from a total of 32,844 LSOAs, only 10,147 had a presence of either FGRs, gambling or casino retailers. This introduced the issue of which LSOAs to include in the analysis. Removing all the LSOAs with no retail floorspace would introduce a bias because this research is interested in both presence and absence of the two groups of retailers' provisioning. Therefore, this paper adopted two different retail configurations. The first analysis included all LSOAs regardless of presence or absence of both retail groups. The second retail configuration included all areas which had presence of either gambling, casino or food retailers, to show the influence of commercialisation on their location preferences. FGRs and gambling retail location preferences vis-à-vis area deprivation were assessed using Kernel density estimation (Reigadinha et al., 2017; Silverman, 1986), correlation, analysis of variance (ANOVA) and binary logistic regression (BLR). 


\subsection{Results}

\subsection{Descriptive Statistics}

Table 1 shows the provisioning of FGRs outlets, FGR floorspaces, gambling and casino retail outlets across the 3 deprivation indicators. The distribution of gambling and casinos provisioning follow a relatively similar linear pattern with decile 1 (the most deprived $10 \%$ LSOAs) having the highest outlets and as deprivation reduces, the number of gambling and casinos outlets reduces generally.

Insert table 1 here

In addition, the proportion of gambling and casino outlets in decile 1 compared to decile 10 (the least deprived 10\% LSOAs) is between two and five times higher across the 3 deprivation indicators, showing a very disproportionately high presence in deprived neighbourhoods compared to their counterparts in the least deprived neighbourhoods. Different distribution patterns for FGR floorspaces were unearthed in table 1. Decile 4, which is a moderately deprived decile, has the highest distributions of floorspace for income deprivation while decile 3 has the highest floorspace for education deprivation.

Only across education deprivation is the floorspace in decile 1 highest across all classification. In addition, the difference between the distributions in the most and least deprived deciles is not up to 2.5 times across all deprivation indicators.

\subsection{Spatial patterns of FGRs and gambling retail outlets in England}

Figures 1A, 1B and 1C show the KDE (hotspot) maps for FGR floorspaces, gambling and casino outlets combined and only casino outlets in England at LSOA geography respectively. From figure 1B, pockets of concentrations are observed in overall gambling 
provision in the North West, North East, West Yorkshire, London and around the coastal areas in the South and South East. From figure 1C, high concentration of casinos is observed along the coastal lines of England as well as South East, London, Midlands, Yorkshire, Manchester and Newcastle. Likewise, figure 1A for FGRs shows similar patterns compared to figure 1B but also very high concentration in the South e.g. Brighton, Portsmouth and Bournemouth. Figure 1D on the other hand shows the pattern of deprivation in England by mapping the IMD deciles. Comparison reveal that many of the most deprived LSOAs also coincide with the areas with the highest concentrations of gambling and casino locations as well as FGR floorspaces in England.

\section{Insert figure 1 here}

For better visualisation of the relationships between retail locations and deprivation, figure 2 and 3 show the KDE maps for overall gambling provisioning (gambling, casinos and family entertainment centres) and FGR floorspace and the IMD for Leeds and London respectively. From Figure 2A, the centre of Leeds has a very high concentration of overall gambling and casino outlets and with distance from the centre, the density reduces. Also, in figure $2 \mathrm{~B}$, areas at the centre of Leeds have high presence of FGR floorspace, but the density is not concentrated within the centre, it stretches both North, South, East and West of Leeds. These areas with high presence of floorspace and casino provisioning further coincides with areas of high deprivation from figure $2 \mathrm{C}$, which shows patterns of deprivation in Leeds. From figure $3 \mathrm{~A}$ and $3 \mathrm{~B}$, the overall gambling and floorspace provisioning show quite similar patterns, but food provisioning (3B) appears to have greater geographical spread compared to gambling provision. Similar to the patterns in Leeds, these high-density areas mostly match with areas of high deprivation as shown in figure 3C. Irrespective of these general patterns, there are still some very deprived areas 
in London which have low presence of floorspace provisioning but high gambling provisioning e.g. Peckham, Livesey, New Cross. This is also similar with Leeds e.g. Chapel Allerton. The findings show that there are also differences in these retail location patterns and deprivation.

Insert figure 2 here

Insert figure 3 here

\subsection{Association between gambling and FGRs and deprivation}

Results of the test of association between the 3 deprivation domain ranks and rank of gambling and casino outlets \%o (per 1000) persons for all LSOAs and commercial LSOAs (see table 2) reveals a highly significant positive association between income, employment and education for all LSOAs $(\mathrm{p}<.001)$. Similarly, there is a highly significant positive relationship between FGRs and income, employment and education deprivation $(\mathrm{p}<.001)$ in all areas. Thus, overall, the higher the deprivation, the higher the distribution of both groups of retailers, but examination of the coefficients reveals a higher correlation with gambling retailers compared to FGRs.

For commercial area analysis, the relationship between income, employment and education and availability of gambling opportunities further shows positive and stronger coefficients $(\mathrm{p}<.001)$ generally. Likewise, location of casinos also shows significant and higher positive and stronger associations with employment and education deprivation, while for income deprivation the correlations are slightly lower. Therefore, generally, as deprivation increases, gambling and casino provisions also increases. Interestingly, the results for FGR indicate a highly significant negative association $(p<.001)$ with income and employment whereas no association is found between education deprivation and FGR 
floorspace i.e. contrary to gambling retailers, food floorspaces are more assessible in affluent income and employment commercial neighbourhoods compared to deprived commercial neighbourhoods (table 2). However, education deprivation has no relationship with floorspace provisioning across commercial areas.

Insert table 2 here

\subsection{Mean distribution of food and gambling retailers and deprivation}

Figure 4 are the means plots showing the patterns of distribution of the 2 groups of retailers' outlets and floorspaces across deciles $1-10$ (the most and least deprived $10 \%$ LSOAs) for income, employment and education deprivation domains for all areas and commercial areas.

\section{Insert figure 4 here}

For both LSOA considerations, gambling and outlets in decile 1 have the highest mean and the means generally reduces as deprivation reduces. For casinos, the patterns are almost similar with decile 1 having the highest mean and the outlets reduces as deprivation reduces generally. Combining casinos and gambling outlets shows relatively similar patterns. For all areas, the mean of FGR floorspace is highest in LSOAs in deciles 4 and 3 (which are not the most deprived LSOAs) for income and education deprivation respectively, while for employment deprivation, the most deprived decile has the highest mean floorspace provisioning. For commercial areas, the patterns are similar compared to the all-area analysis for FGR floorspace. For income and education deprivation, the mid deprived deciles have better provisioning, while for employment, the most deprived decile has the best provision. Irrespective, overall, comparison reveals that there is a more 
pronounced concentration of gambling and casino retailers in deprived areas compared to FGRs floorspaces and FGR outlets.

\subsection{ANOVA analysis for mean distribution}

Mean differences between deciles were assessed using a Welch one-way ANOVA (because data violated assumption of homogeneity of variances). Results indicate highly significant differences between the two groups of retailers outlets' means across income, employment and education deprivation indicators $(p<.001)$ for both LSOA considerations.

Insert table 3

Insert table 4

Insert table 5

Table $3-5$ show the result of the post-hoc test comparing the mean differences of gambling, casino and foods provisioning between decile 1 and 2 (the two most deprived deciles) to all other deciles across the three deprivation indicators. For all areas, comparison show that the mean difference for gambling outlets is not significantly different between the decile 1 and 2, which are the most deprived deciles. Further, the means of decile 1 and 2 are significantly higher compared to decile $5-10$ for income and $4-10$ for education deprivation. More importantly, the pattern is more defined with employment deprivation where the mean in the most deprived areas (decile 1) is significantly different compared to all other deciles $(\mathrm{p}<.001)$. Similar patterns are also observed with the merging of gambling and casino outlets across the deprivation indications. Likewise, looking at casinos, generally, the mean difference in decile 1 is 
significantly higher compared to all other deciles for employment across all area analysis. Whereas, for education, only the least deprived $10 \%$ and $20 \%$ LSOAs $(9-10)$ have significantly lower means compared to the most deprived 10\% LSOAs (decile 1). For income, the mean difference in decile 1 is significantly higher compared to decile 3,5 and 7 to 10 .

For FGR floorspace provisioning looking at all areas, there are no significant differences in the mean of decile 1 compared to deciles $2,3,4,5$, and 6 for income deprivation, decile 2, 3, and 4 for employment deprivation and decile 2, 3, 4, and 6 for education deprivation. In addition, decile 1 has a significantly higher mean compared to the affluent deciles (7, 8,9 and 10) across the three deprivation indicators. The results show that the most and moderately deprive neighbourhoods have similar floorspace provisioning while the most deprived areas have better floorspace provisioning compared to the affluent areas in England.

For commercial area analysis, tables 3 to 5 reveal relatively similar provision of overall gambling and casino outlets with the all area analysis. For gambling and the combined casino and gambling outlets, decile 1 has a significantly higher mean compared to the affluent deciles $(\mathrm{p}<.05)$. Hence, the most deprived commercial areas also have the highest presence of gambling and casino outlets compared to their counterpart in affluent localities. On the other hand, for FGR floorspace, comparison reveal no significant differences between the mean in decile 1 and 2 compared to all other deciles for income deprivation. For employment and education deprivation, comparison show that the mean floorspace in decile 1 is significantly higher compared to the most affluent deciles ( $p$ $<.001)$ and statistically similar to the mid deprived deciles $(\mathrm{p}>.05)$. Consequently, among commercial LSOAs, the FGR floorspace provisioning favour deprived LSOAs 
compared to the affluent LSOAs, but statistically similar across deprived and mid deprived neighbourhoods.

Overall comparison of mean distribution of FGR floorspaces and overall gambling and casino locations reveal that although there is a high presence of floorspaces in deprived compared to the affluent LSOAs, the concentration is very much pronounced with gambling and casino retailers. Even between the deprived areas, gambling provision are higher in the areas with the highest deprivation characteristics.

\subsection{Regression analysis between deprivation, FGR and gambling provisioning}

To further understand the complex relationships between these groups of retailers and deprivation, table 6 shows the odds ratio from the binomial logistic regression between presence and absence of FGR floorspace, gambling and casino retailers in income, employment and education deprivation domains for both LSOA considerations. For this analysis, decile 10 (the least deprived 10\% LSOAs) was used as the reference class for the 3 indicators. For all areas, the odds of presence of a gambling and casino outlet in income decile 1 is 5.8 and 2.4 times respectively compared to odds of their presence in the reference decile. From table 6, the likelihood of presence of casino and gambling outlets in employment deprivation decile 1 compared to decile 10 is between 2.7 and 4 times higher.

For education deprivation, the odds of presence of gambling or casino outlets is 2.6 and 3.1 times in decile 1 compared to the decile 10 respectively. Also, as income, employment and education deprivation reduce, the likelihood of gambling outlets also reduces for all areas although only decile 1 and 10 is significant for casino outlets for income and employment deprivation. Interestingly, the impact of education deprivation is more 
pronounced with casino outlets which reveal higher odds or presence in decile 1, 2, 3 and 4 compared to other indicators $(\mathrm{p}<.001)$.

Considering the results for FGRs in relation to all LSOAs (table 6) for income deprivation, the odds of presence of FGR outlet in decile 5 is almost 2 times compared to decile 10 . Decile 5, a moderately deprived decile, has the highest likelihood of presence of food retailers. For employment deprivation, decile 4 has the highest odds of presence of FGRs (1.5 times) compared to decile 10 across all deciles. Likewise, for education, decile 3 has the highest likelihood of FGR presence (over 1.5 times) compared to the reference decile across all education deprivation deciles (table 6). Hence, the highest likelihood of presence of FGR floorspace across the 3 deprivation indicators are in the middle and moderately deprived deciles.

The results of the regression for only commercial areas for both groups of retailers are also shown in table 6. For gambling retailers, the patterns across the 3-deprivation domains remain the same compared with that of all areas, but the odds of likelihood are higher in commercial deprived areas whereas, for casino outlets, the odds ratio are lower. In addition, only decile 1 has a likelihood of increase presence of casino compared to decile 10. In decile 3-9, interestingly, the odds of absence of a casino is higher compared to the most affluent decile. However, the results of the commercial area analysis for FGRs shows a very different pattern. From table 6 , the odds of presence of FGRs in the reference group (decile 10) is $80 \%, 77 \%$ and $65 \%$ higher for income, employment and education deprivation respectively compared to decile 1 (the most deprived decile), showing that the least deprived commercial areas have a higher likelihood of presence of food outlets compared to the most and moderately deprived commercial areas. 
Insert table 6 here

\subsection{Discussion and Conclusion}

This study set out to examine the notion of deliberate targeting ascribed to gambling and casino retailers by comparing the location patterns of gambling provisioning to FGRs relative to socio-economic variations in England. The KDE and correlations results reveal a significant concentration of gambling and casino locations in the most deprived areas, which are mostly traditional and historical urban centres in England. Interestingly, the geographical locations of casinos and family entertainment centres are predominant along the coastlines as well as historical urban centres in England, similar to other findings in the UK (Wardle et al., 2014). The KDE visualisations for areas in Leeds and London further confirmed that areas of high deprivation also coincide with areas of high overall gambling provisioning.

Analysis of variance revealed highly significant concentrations of gambling retailers in the most deprived neighbourhoods compared to affluent communities. Likewise, these patterns were also confirmed by similar analysis on casino locations, although for the latter, the patterns are more pronounced with employment deprivation. These patterns are also confirmed in the results of the binomial logistic regression, with the highest likelihood of presence of gambling and casino outlets in the most deprived neighbourhoods in contrast to the least deprived areas. The results suggest a clear concentration and prevalence of gambling and casino provisioning in deprived neighbourhoods, consistent with international evidence (Gilliland and Ross, 2005; Wheeler et al., 2006; Young et al., 2009) and UK studies (Wardle et al., 2014). 
Similarly, floorspace provisioning showed comparable patterns in England, with higher concentrations in deprived areas. These was also further confirmed by visualisation in Leeds and London, although some deprived areas had poor provisioning. These concentrations are also positively correlated with the three deprivation indicators for FGRs provision in all areas. The ANOVA result further corroborates the findings of the correlation which reveal a significantly high FGR floorspace provisioning in the most deprived areas compared to the affluent neighbourhoods across income, employment and education deprivation. These findings are consistent with studies carried out in the UK and elsewhere (Black et al., 2012; Cummins and Macintyre, 2002; Smoyer-Tomic et al., 2006; Smith et al., 2009), but contrary to a UK and international studies which found poor food provisioning in deprived areas (Zenk et al., 2005; Larson and Gilliland, 2008; Gordon et al., 2011; Burgoine et al., 2017). Accordingly, there is a possibility that the location of both gambling, casino and food floorspace reflects the abundant opportunities for retail development and planning regulations in these highly deprived neighbourhoods (Whysall, 2014). This clearly supports the principle of minimum differentiation as it demonstrates that food, gambling and casino retailers may be concentrated in deprived areas compared to the very affluent neighbourhoods because of spatial competition which encourages the agglomeration of similar retailers in the same location (Hotelling 1929; Nelson, 1954; Pascal and McCall, 1980; Reigadinha et al., 2017) because clustering of similar retailers reduces risk and encourage healthy competition. In addition, the concentration of both food provisioning observed in historical commercial hubs in England as well as City of London and centre of Leeds emphasises the importance of centrality, which is supported by the bid rent theory. 
To further examine these relationships, evidence from the literature suggests that land use/zoning regulations and accessibility exert significant influences on existing retail structures (Smoyer-Tomic et al., 2006; Black et al., 2011; Young et al., 2009). This study further explored the influence of commercial land use on these retailers' location preferences in England. The results for gambling and casino retailers across the three deprivation indicators reveal similar patterns with strongest linkages with area deprivation in commercial tracts. Logistic regression further shows that the prevalence of gambling and casinos is very high in the most deprived neighbourhoods. Further emphasising that deprived commercial neighbourhoods have higher concentrations of these retailers and these areas appear to be preferential locations.

Conversely, correlations result for FGRs show a very different pattern for commercial areas compared to all areas with negative linkages with floorspace and deprivation especially for income and employment deprivation. The results of the ANOVA mean analysis further reveal that even though the means are higher for mid deprived commercial locations, provisioning is statistically similar across these commercial neighbourhoods for income deprivation. Whereas, for employment and education deprivation, deprived and mid deprived areas have statistical similar provisioning, while affluent commercial neighbourhoods have statistically lower floorspace provisioning. Further echoing the results of comparable studies which allude that deprived and middeprived areas have better food provisioning (Cummins and Macintyre, 2002; SmoyerTomic et al., 2006; Smith et al., 2009; Black et al., 2012).

Logistic regression which compared presence or absence of floorspace across all LSOAs and commercial LSOAs showed highest likelihood of FGR floorspace in mid-deprived and affluent localities respectively in England. Overall, deprived areas have more 
floorspace, but lesser actual food outlets from this study. Undoubtedly, deprived communities have greater provision of FGR floor space because of large presence of superstores ( $>30,000$ sqft). Unfortunately, these stores can lead to closure of pre-existing stores which would only further worsen food provisioning, and lead to limited food options and choices in deprived localities through its displacement of small stores (Clarke et al., 2002). The importance of choice is also highlighted by a study which discovered that asides proximity, other factors such as price, ethical consumption and individual circumstances are important in food provisioning (Hillier et al., 2015). Therefore, deprived areas which are highly characterised by hard pressed individuals who do not have reliable means of transport might have restricted choices. Therefore, preference should be given to multiple smaller store formats (Clarke et al, 2002).

Overall, comparison of FGRs and casino and gambling locations shows that although there is a positive correlation between both sets of retailers, gambling and casino outlets are more prevalent in deprived areas. In addition, the analysis of means and logistic regression shows a greater preference for deprived localities by gambling and casino businesses, as higher concentration of casino and gambling provision are found in these areas. Therefore, FGRs are more ubiquitous across the socio-economic spectrum and have relatively similar distribution. However, gambling retailers, who reportedly draw greater demand from areas with large proportions of deprived individuals (Wardle et al., 2010), have higher prevalence in deprived areas. Furthermore, after accounting for the effect of commercialisation (by examining only LSOAs with gambling, casino or food retail outlets and floorspaces), gambling retailers are still more prevalent in the most deprived commercial locations. This lends more credence to the notion of deliberate and targeted concentration of gambling opportunities in deprived communities. It is possible 
that the attractions for gambling retailers in these locations are the deprivation-related area characteristics. The location patterns can also be as a result of the available vacant premises in these areas (Department of Health, 1991; Townshend 2017). Not only that, lower rents in deprived neighbourhoods and community opposition in better off neighbourhoods might also account for the socio-economic divide in gambling and casino locations.

\subsection{Implications for Policy}

This research has noted a peculiar pattern of retail provisioning in respect to area deprivation. The linkages are complex and interwoven, as this research has highlighted. The critical comparative approach adopted by this study is a novel approach which has not previously been adopted in previous UK studies and clearly reveals salient similarities and peculiarities in the location preferences of FGRs, gambling and casino outlets. From the general point of view, irrespective of the similarities in the location patterns of these two retail groups, there seems to be strong evidence that, aside from zoning patterns, there are other area characteristics that seem to be attracting gambling and casino businesses to these deprived communities. These could be the individual characteristics of residents of the areas.

Compared to previous studies that carried out one-sided analysis, this study addresses the notion of deliberate targeting and arrived at salient implications for policy. Presently, a number of steps have been taken to address the dangers of proliferation of gambling in terms of restricting stakes on gambling machines (Woodhouse, 2018). A reduction, albeit a good decision, is not enough to address the harm associated with participation. Rather, actions to address the indiscriminate proliferation of gambling outlets are needed, including stringent control of new venues. 
For FGRs, the overall provisioning favours deprived communities, but this study has highlighted some form of under provisioning, which might limit choices of underprivilege inhabitants by the effect of very large food store formats. This could further worsen the inequalities in health in England's deprived neighbourhoods, as these communities will have limited food choices. Therefore, public health can be improved by tailoring policies at local level to address FGR locations and also tackle socio-economic barriers. Steps to achieving this might be difficult because retailers' location selection are market-based decisions and restricting their options might have unintended adverse effects. In addition, high street shop closure has become very rampart in recent times partly driven by shift to online retailing.

\subsection{Limitations and future research}

This study has some limitations. Provisioning did not consider distances and interactions between origin of demand and destination. A method which would factor in these parameters would further improve the results of this study. Likewise, catchment area consideration would also improve the results of this paper. It is important that comparative studies adopt similar metrics to prevent undue or overbearing influence of different metrics. Therefore, comparing floorspace of FGRs to physical locations of gambling casinos might introduce a bias to the results, but floorspace is a very adequate measure of provisioning for FGRs. In addition, it is common knowledge that the catchment area of a betting shop will be different from that of a big-out of town store. Likewise, a convenience store is smaller than a big out-of-town supermarket and the presence of such out-of-town stores, gambling or casino venues might attract nonlocalised patrons based on the concept of range of goods (Berry, 1967). Therefore, future studies should develop more robust methods that would address these limitations. 
Likewise, the study would further benefit from incorporating theories on consumer vulnerability. More importantly, a qualitative approach would further improve these results, although this might be difficult because there is a strong possibility that gambling, and casino retailers would only disclose socially acceptable marketing strategies.

\section{References}

Abbott MW, Volberg R A, Bellringer M and Reith G (2004). A review of research on aspects of problem gambling: final report. Prepared for the Responsibility in Gambling Trust, UK. Gambling Research Centre, Auckland University of Technology, Auckland, NZ.

Ghosh, A (1994). Retail location: A micro-scale perspective: Stephen Brown Avebury Aldershot 315 pp. Journal of Retailing and Consumer Services, 1(2) pp 117 - 118.

BBC (2018). William Hill fined $£ 6.2 \mathrm{~m}$ by Gambling Commission for lax controls. [Online]. Available at: https://www.bbc.co.uk/news/business-43124258 [Accessed 26/11/2018]

Berry B J (1967). Geography of Market Centers and Retail Distribution. Englewood Cliffs N.J.: Prentice-Hall.

Black C, Ntani G, Kenny R, Tinati T, Jarman M, Lawrence W, Barker M, Inskip H, Cooper C, Moon G and Baird, J. (2012) Variety and quality of healthy foods differ according to neighbourhood deprivation. Health and place, 18(6): 1292-1299. https://doi.org/10.1016/j.healthplace.2012.09.003

Black JL, Carpiano RM, Fleming S and Lauster N. (2011) Exploring the distribution of food stores in British Columbia: associations with neighbourhood sociodemographic factors and urban form. Health and Place, 17(4): 961-970. https://doi.org/10.1016/j.healthplace.2011.04.002

Block JP, Scribner RA and DeSalvo KB (2004) Fast food, race/ethnicity, and income. American journal of preventive medicine, 27(3): 211-217. https://doi.org/10.1016/j.amepre.2004.06.007

Bodicoat DH, Carter P, Comber A, Edwardson C, Gray LJ, Hill S, Webb D, Yates T, Davies MJ and Khunti K (2015) Is the number of fast-food outlets in the neighbourhood related to screen-detected type 2 diabetes mellitus and associated risk factors?. Public health nutrition, 18(9): 1698-1705. https://doi.org/10.1017/S1368980014002316

Brown S (1992) Retail Location: A Micro-Scale Perspective, Avebery.

Burgoine T, Mackenbach JD, Lakerveld J, Forouhi NG, Griffin SJ, Brage S, Wareham NJ and Monsivais P (2017) Interplay of socioeconomic status and supermarket distance is associated with excess obesity risk: a UK cross-sectional study. 
International journal of environmental research and public health, 14(11): 1290. https://doi.org/10.3390/ijerph14111290

Burns CM and Inglis AD (2007) Measuring food access in Melbourne: access to healthy and fast foods by car, bus and foot in an urban municipality in Melbourne. Health and place, 13(4): 877-885. https://doi.org/10.1016/j.healthplace.2007.02.005

Christaller W (1966) Central places in southern Germany. Prentice-Hall.

Clarke G, Eyre H and Guy C (2002) Deriving indicators of access to food retail provision in British cities: studies of Cardiff, Leeds and Bradford. Urban Studies, 39(11): 2041-2060.

Cummins S and Macintyre S (2002) A systematic study of an urban foodscape: the price and availability of food in greater Glasgow. Urban Studies, 39(11): 2115-2130. https://doi.org/10.1080/0042098022000011399

Davies R and Rogers D eds. (1984) Store Location and Store Assessment Research. John Wiley, Chichester.

Department of Health (1999) Improving shopping access for people living in deprived neighbourhoods. Discussion Paper of Policy Action Team, 13 of the National Strategy for Neighbourhood Renewal, Department of Health, London. Available at:

http://webarchive.nationalarchives.gov.uk/20100407174644/http://www.cabinetof fice.gov.uk/media/cabinetoffice/social_exclusion task force/assets/publications 1997 to_2006/pat_report_13.pdf [Accessed 21/02/2018]

Dowling N, Smith D and Thomas T 2005. Electronic gaming machines: are they the 'crack-cocaine' of gambling?. Addiction, 100(1): 33-45. https://doi.org/10.1111/j.1360-0443.2005.00962.x

Foxall G (1990) Consumer Psychology in Behavioural Perspective. London: Routledge.

Gambling Act (2005) Gaming Act [Online]. Available at: https://www.legislation.gov.uk/ukpga/2005/19/introduction [Accessed on: 21/02/2018]

Gambling Commission (2018) SkyBet to pay $£ 1 \mathrm{~m}$ penalty package for social responsibility failures. [Online]. Available at: https://www.gamblingcommission.gov.uk/news-action-andstatistics/news/2018/SkyBet-to-pay-1m-penalty.aspx [Accessed: 26/11/2018].

Ghosh A and Craig CS (1983) Formulating retail location strategy in a changing environment. The Journal of Marketing, pp.56-68. https://doi.org/10.1177/002224298304700307

Gilliland JA and Ross NA (2005) Opportunities for video lottery terminal gambling in Montréal: An environmental analysis. Canadian Journal of Public Health/Revue Canadienne de Sante'e Publique, pp.55-59. 
Reimers, V. and Clulow, V., 2004. Retail concentration: a comparison of spatial convenience in shopping strips and shopping centres. Journal of Retailing and Consumer services, 11(4), pp.207-221.

Gordon C, Purciel-Hill M, Ghai NR, Kaufman L, Graham R and Van Wye G (2011) Measuring food deserts in New York City's low-income neighborhoods. Health and place, 17(2): 696-700. https://doi.org/10.1016/j.healthplace.2010.12.012

Gould AC, Apparicio P and Cloutier MS (2012) Classifying neighbourhoods by level of access to stores selling fresh fruit and vegetables and groceries: identifying problematic areas in the city of Gatineau, Quebec. Can J Public Health, 103(6): 433-437. https://doi.org/10.1007/BF03405633

Guardian (2015) Paddy Power and Betfair merger agreed. [Online] Available at: https://www.theguardian.com/business/2015/sep/08/paddy-power-and-betfairmerger-agreed [Accessed 30/11/2018]

Guy C, Clarke G and Eyre H (2004) Food retail change and the growth of food deserts: a case study of Cardiff. International Journal of Retail and Distribution Management, 32(2): 72-88. https://doi.org/10.1108/09590550410521752

Haig, R. M, 1927. Regional survey of New York and its environs. New York City Planning Commission.

Hillier, A., Smith, T., Cannuscio, C.C., Karpyn, A. and Glanz, K., 2015. A discrete choice approach to modeling food store access. Environment and Planning B: Planning and Design, 42(2), pp.263-278.

Hotelling H (1929) Stability in competition. In the collected economics articles of Harold Hotelling. New York: Springer pp. 50-63.

Hoyer D and Maclnnis J (2010) Consumer Behaviour. International Edition fifth edition. South-Western.

Kubrin CE, Squires GD, Graves SM and Ousey GC (2011) Does fringe banking exacerbate neighborhood crime rates? Criminology and Public Policy, 10(2): 437466. https://doi.org/10.1111/j.1745-9133.2011.00719.x

Larsen K and Gilliland J (2008) Mapping the evolution of 'food deserts' in a Canadian city: Supermarket accessibility in London, Ontario, 1961-2005. International Journal of Health Geographics, 7(1): p.16. https://doi.org/10.1186/1476-072X-7-16

Nakaya T, Fotheringham AS, Hanaoka K, Clarke G, Ballas D and Yano K (2007) Combining microsimulation and spatial interaction models for retail location analysis. Journal of Geographical Systems, 9(4): 345-369. https://doi.org/10.1007/s10109-007-0052-2

National Planning Policy Framework (NPPF) (2012). Department for Communities and Local Government [online] Available at: https://www.gov.uk/government/uploads/system/uploads/attachment data/file/607 7/2116950.pdf [Accessed: 18/06/2018]

Nelson RL (1958) The selection of retail locations. FW Dodge, New York. 
Pascal AH and McCall JJ (1980) Agglomeration economies, search costs, and industrial location. Journal of Urban Economics, 8(3): 383-388. https://doi.org/10.1016/00941190(80)90038-8

Pidd H (2017) Gambling is an industry that feasts on the poor and vulnerable [Online] Available at: https://www.theguardian.com/commentisfree/2017/sep/05/gamblingindustry-feasts-on-poor-vulnerable-helen-pidd [Accessed 05/02/2019]

Portas M (2011) The Portas Review: An independent review into the future of our high streets. Department for Business, Innovation and Skills.

Prime Minister's Strategic Unit (2005) Improving the prospects of people living in areas of multiple deprivation in England. London: Prime Minister's Strategy Unit.

Robitaille É and Herjean P (2008) An analysis of the accessibility of video lottery terminals: the case of Montréal. International Journal of Health Geographics, 7(1): 2 https://doi.org/10.1186/1476-072X-7-2

Reigadinha, T., Godinho, P. and Dias, J., 2017. Portuguese food retailers-Exploring three classic theories of retail location. Journal of Retailing and Consumer Services, 34, pp.102-116.

Schiller R K (1988) Retail Decentralization. A Property View. Geographical Journal, pp.17-19.

Schiller RK (1971) Location trends of specialist services. Regional Studies, 5(1): 1-10. https://doi.org/10.1080/09595237100185011

Sharkey JR and Horel S (2008) Neighbourhood socioeconomic deprivation and minority composition are associated with better potential spatial access to the ground-truthed food environment in a large rural area. The Journal of nutrition, 138(3): 620-627. https://doi.org/10.1093/jn/138.3.620

Silverman B W (1986). Density estimation for statistics and data analysis. Chapman and Hall, London, UK

Smith DM, Cummins S, Taylor M, Dawson J, Marshall D, Sparks L and Anderson AS (2009) Neighbourhood food environment and area deprivation: spatial accessibility to grocery stores selling fresh fruit and vegetables in urban and rural settings. International Journal of Epidemiology, 39(1), pp.277-284. https://doi.org/10.1093/ije/dyp221

Smith T, Noble M, Noble S, Wright G, Mclennan D and Plunkett E, (2015) The English indices of deprivation. Technical Report. Department of Communities and Local Government. [Online] Available at: https://assets.publishing.service.gov.uk/government/uploads/system/uploads/attac hment data/file/464485/English Indices of Deprivation 2015 - TechnicalReport.pdf [Accessed: 18/02/2019]

Smoyer-Tomic KE, Spence JC and Amrhein C (2006) Food deserts in the prairies? Supermarket accessibility and neighbourhood need in Edmonton, Canada. The 
Professional Geographer, 58(3), pp.307-326. https://doi.org/10.1111/j.1467$\underline{9272.2006 .00570 . \mathrm{x}}$

Townshend, T G (2017). Toxic high streets. Journal of urban Design, 22(2): 167-186. https://doi.org/10.1080/13574809.2015.1106916

Wardle H, Keily R, Astbury G and Reith G (2014) 'Risky places?': Mapping gambling machine density and socio-economic deprivation. Journal of Gambling Studies, 30(1): 201-212. https://doi.org/10.1007/s10899-012-9349-2

Wardle H, Moody A, Griffiths M, Orford J and Volberg R (2010) Gambling Prevalence Survey 2010.

Webber M J (1972) The Impact of Uncertainty on Location. MIT Press, Cambridge, MA

Wheeler BW, Rigby JE and Huriwai T (2006) Problem gambling risk factor geography in New Zealand. Health and place, 12(1): 86-96. https://doi.org/10.1016/j.healthplace.2004.10.011

Whysall P (1995). Regenerating inner city shopping centres: the British experience. Journal of Retailing and Consumer Services, 2(1): 3-13.

Whysall P (2014) Retailers and deprivation: An exploratory study: In British Academy of Management Conference, Belfast, September 2014.

Wood S, Lowe M, and Wrigley N (2006) Life after PPG6-Recent UK food retailer responses to planning regulation tightening. International Review of Retail, Distribution and Consumer Research, 16(1): 23-41. https://doi.org/10.1080/09593960500453435

Woodhouse J (2018) Fixed odds betting terminals. [online] Briefing paper number 06946, 16 November. House of Commons Library. Available at: http://researchbriefings.files.parliament.uk/documents/SN06946/SN06946.pdf [Accessed 12/12/2018].

Wrigley N (2002) Food deserts in British cities: policy contexts and research priorities. Urban Studies, 39(11): 2029-2040. https://doi.org/10.1080/0042098022000011344

Young M, Lamb D and Doran B (2009) Mountains and Molehills: a spatiotemporal analysis of poker machine expenditure in the Northern Territory of Australia. $\begin{array}{lll}\text { Australian } & \text { Geographer, 249-269. }\end{array}$ https://doi.org/10.1080/00049180903127721

Zenk SN, Schulz AJ, Israel BA, James SA, Bao S and Wilson ML (2005) Neighbourhood racial composition, neighbourhood poverty, and the spatial accessibility of supermarkets in metropolitan Detroit. American journal of public health, 95(4): 660-667. 
Table 1 Distribution of FGRs, gambling and casinos across income, employment and education deprivation deciles

\begin{tabular}{|c|c|c|c|c|c|}
\hline & $\begin{array}{c}\text { FGRs } \\
\text { Outlets (\%) } \\
\end{array}$ & $\begin{array}{c}\text { FGR } \\
\text { Floorspaces } \\
(\%) \\
\end{array}$ & $\begin{array}{c}\text { Gambling Outlets } \\
(\%)\end{array}$ & $\begin{array}{c}\text { Casinos } \\
(\%)\end{array}$ & $\begin{array}{c}\text { Gambling outlets } \\
\text { \& Casino }(\%)\end{array}$ \\
\hline Deciles & & & Income & & \\
\hline 1 & 9.68 & 11.97 & 18.22 & 23.24 & 18.41 \\
\hline 2 & 11.79 & 13.10 & 16.65 & 12.68 & 16.50 \\
\hline 3 & 12.02 & 13.09 & 15.31 & 10.09 & 15.12 \\
\hline 4 & 12.96 & 13.51 & 13.60 & 11.97 & 13.54 \\
\hline 5 & 12.29 & 11.71 & 10.94 & 8.22 & 10.84 \\
\hline 6 & 10.30 & 9.71 & 7.39 & 10.09 & 7.49 \\
\hline 7 & 8.86 & 8.47 & 6.16 & 7.28 & 6.20 \\
\hline 8 & 8.36 & 7.58 & 4.86 & 3.76 & 4.81 \\
\hline 9 & 6.86 & 5.69 & 3.01 & 3.05 & 3.01 \\
\hline \multirow[t]{2}{*}{10} & 6.89 & 5.18 & 3.87 & 9.62 & 4.08 \\
\hline & & & Employment & & \\
\hline 1 & 11.40 & 14.06 & 20.97 & 31.46 & 21.36 \\
\hline 2 & 10.78 & 12.10 & 13.66 & 12.44 & 13.61 \\
\hline 3 & 11.64 & 12.55 & 13.67 & 7.51 & 13.44 \\
\hline 4 & 11.35 & 11.74 & 12.74 & 9.15 & 12.61 \\
\hline 5 & 11.25 & 10.72 & 9.68 & 7.98 & 9.62 \\
\hline 6 & 10.30 & 10.01 & 8.07 & 5.40 & 7.97 \\
\hline 7 & 9.47 & 9.01 & 6.44 & 5.40 & 6.40 \\
\hline 8 & 7.92 & 7.22 & 4.92 & 4.23 & 4.89 \\
\hline 9 & 7.45 & 5.90 & 4.29 & 5.40 & 4.33 \\
\hline \multirow[t]{2}{*}{10} & 8.44 & 6.69 & 5.56 & 11.03 & 5.77 \\
\hline & & & Education & & \\
\hline 1 & 10.40 & 12.62 & 15.47 & 19.01 & 15.61 \\
\hline 2 & 11.11 & 12.63 & 15.68 & 20.19 & 15.85 \\
\hline 3 & 12.04 & 13.03 & 14.05 & 13.85 & 14.04 \\
\hline 4 & 11.04 & 11.40 & 10.83 & 9.62 & 10.78 \\
\hline 5 & 10.03 & 9.64 & 9.89 & 7.51 & 9.80 \\
\hline 6 & 10.60 & 10.74 & 8.84 & 7.98 & 8.81 \\
\hline 7 & 8.99 & 8.67 & 7.06 & 7.28 & 7.06 \\
\hline 8 & 8.67 & 7.76 & 6.49 & 7.04 & 6.51 \\
\hline 9 & 8.97 & 7.40 & 6.31 & 3.76 & 6.21 \\
\hline 10 & 8.13 & 6.11 & 5.39 & 3.76 & 5.33 \\
\hline
\end{tabular}




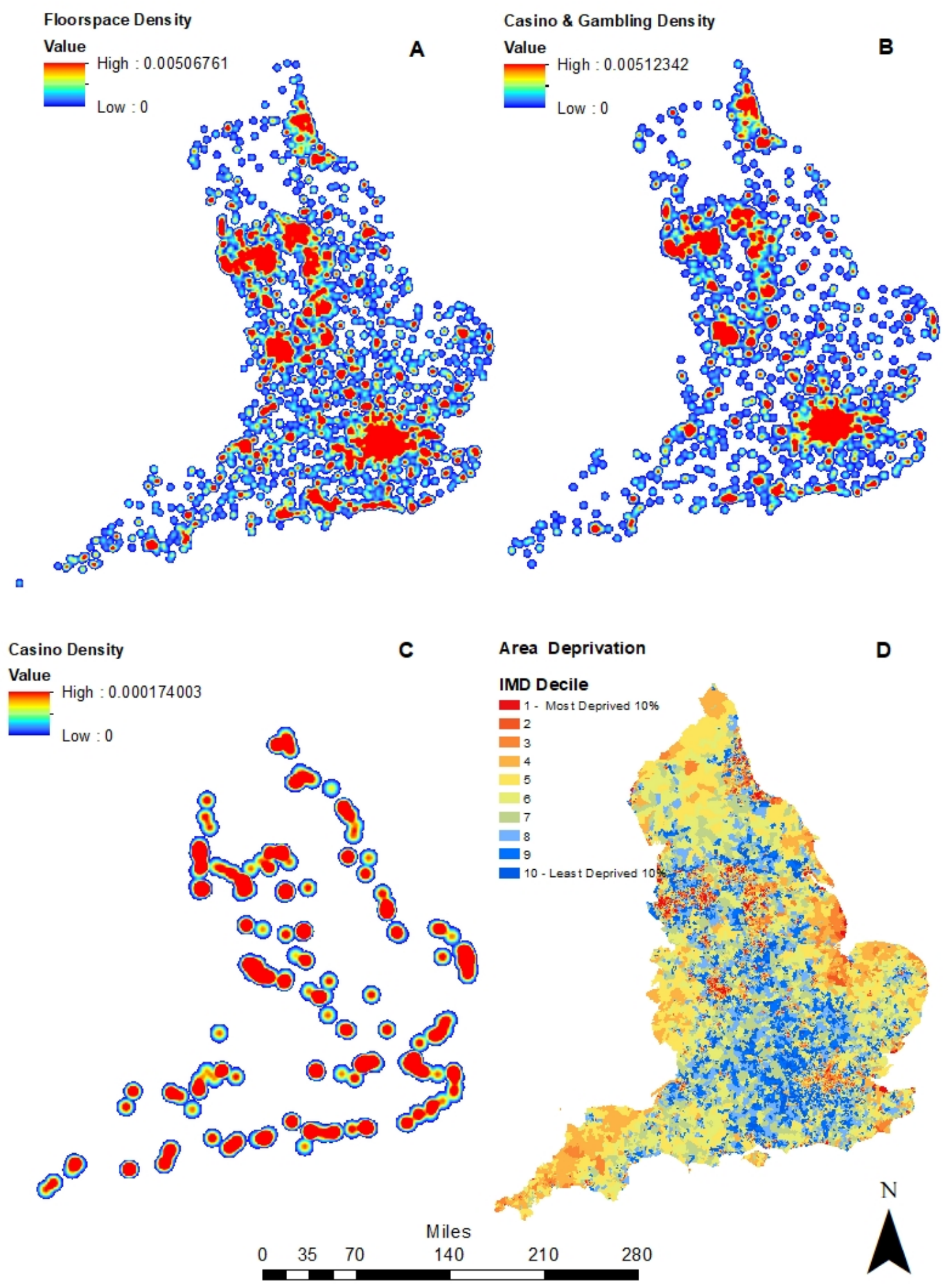

Figure 1: KDE maps for FGR floorspace (1A), gambling \& casino (1B), casino (1C) density maps and area deprivation in England (1D). Contains OS data (C) Crown copyright and database right (2017) and National Statistics data (C) Crown copyright and database right (2015) 


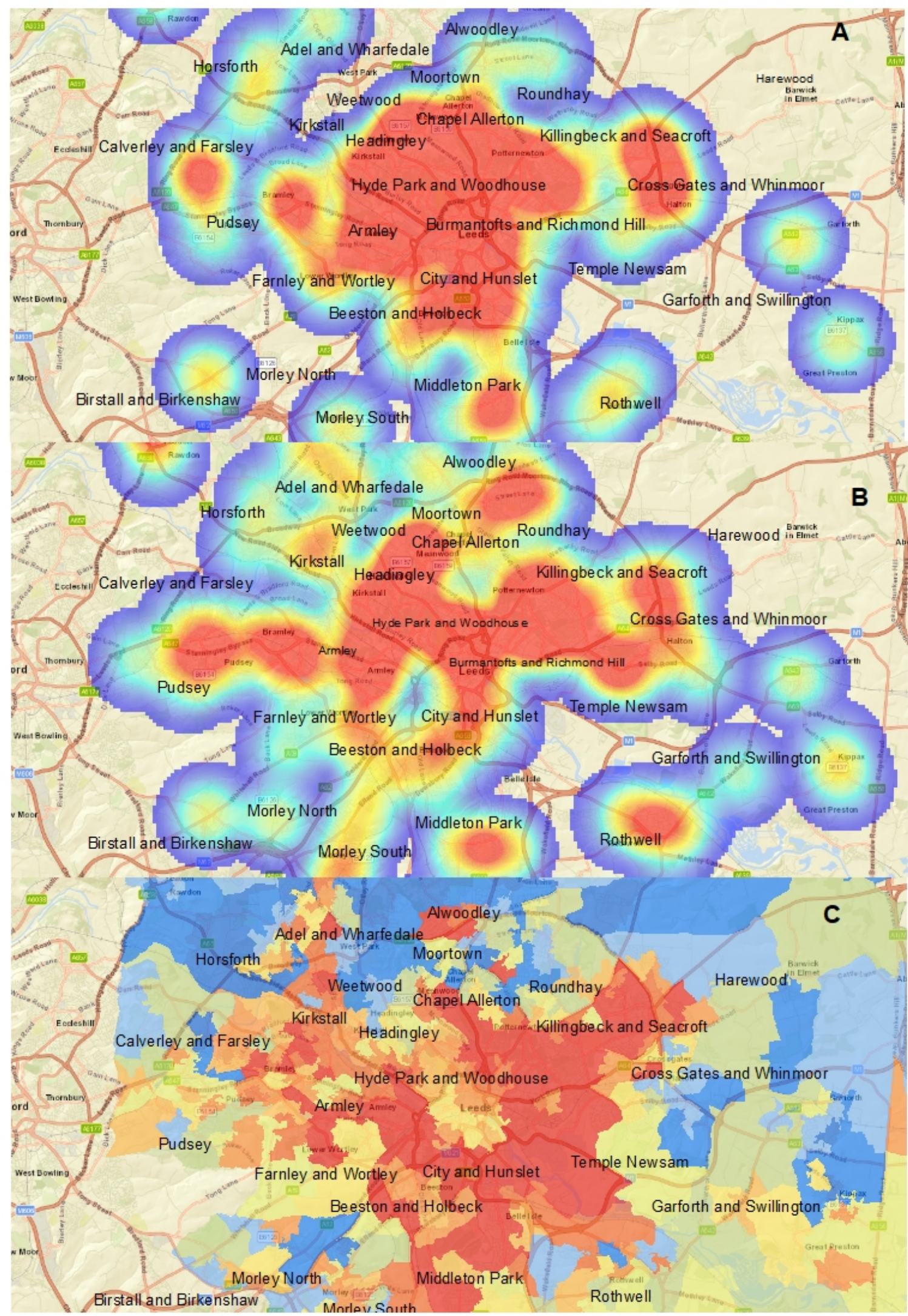

Figure 2 - Maps showing gambling and casino (A), FGR floorspace (B), KDEs and IMD 2015 (C) in Leeds. Contains OS data (C) Crown copyright and database right (2017) and National Statistics data (C) Crown copyright and database right (2015) 


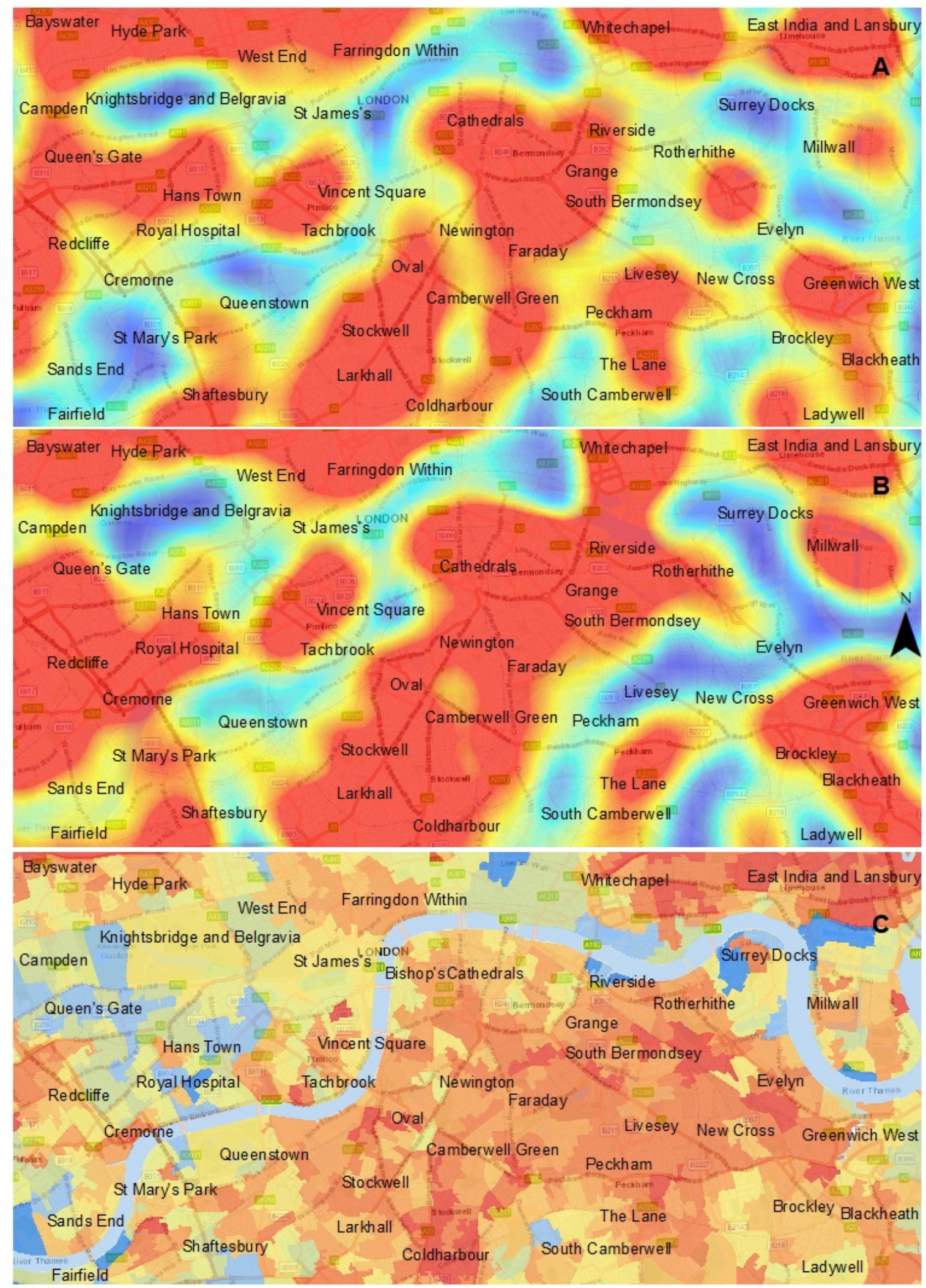

Figure 3 Maps showing overall gambling outlets (A), FGR floorspace (B) and IMD 2015 (C) in London. Contains OS data (C) Crown copyright and database right (2017) and National Statistics data (C) Crown copyright and database right (2015) 
Table 2 Correlation between rank of FGRs outlets, floorspaces, gambling and casinos retailers ' 000 persons and income, employment and education deprivation rank by lower super output areas (LSOAs)

\begin{tabular}{|c|c|c|c|c|c|c|c|c|c|c|c|}
\hline & & \multicolumn{5}{|c|}{ All LSOAs } & \multicolumn{5}{|c|}{ Commercial LSOAs } \\
\hline & & $\begin{array}{c}\text { FGRs } \\
\text { outlets }\end{array}$ & $\begin{array}{c}\text { FGRs } \\
\text { Floorspaces }\end{array}$ & $\begin{array}{c}\text { Gambling } \\
\text { outlets }\end{array}$ & Casinos & $\begin{array}{l}\text { Gambling } \\
\text { \& Casinos }\end{array}$ & FGRs & $\begin{array}{c}\text { FGRs } \\
\text { Floorspaces }\end{array}$ & $\begin{array}{l}\text { Gambling } \\
\text { outlets }\end{array}$ & Casinos & $\begin{array}{c}\text { Gambling \& } \\
\text { Casino }\end{array}$ \\
\hline \multirow{2}{*}{$\begin{array}{l}\text { Income } \\
\text { Deprivation }\end{array}$} & $\mathrm{R}$ & $.064^{* *}$ & $.070^{* *}$ & $.203^{* *}$ & $.036^{* *}$ & $.203^{* *}$ & $-.123^{* *}$ & $-.072^{* *}$ & $.262^{* *}$ & $.035^{* *}$ & $.259^{* *}$ \\
\hline & $\mathrm{N}$ & 32844 & 32844 & 32844 & 32844 & 32844 & 10147 & 10147 & 10147 & 10147 & 10147 \\
\hline \multirow{2}{*}{$\begin{array}{l}\text { Employment } \\
\text { Deprivation }\end{array}$} & $\mathrm{R}$ & $.054^{* *}$ & $.059^{* *}$ & $.180^{* *}$ & $.042^{* *}$ & $.179^{* *}$ & $-.084^{* *}$ & $-.042^{* *}$ & $.244^{* *}$ & $.052^{* *}$ & $.243^{* *}$ \\
\hline & $\mathrm{N}$ & 32844 & 32844 & 32844 & 32844 & 32844 & 10147 & 10147 & 10147 & 10147 & 10147 \\
\hline \multirow{2}{*}{$\begin{array}{l}\text { Education } \\
\text { Deprivation }\end{array}$} & $\mathrm{R}$ & $.042^{* *}$ & $.048^{* *}$ & $.127^{* *}$ & $.043^{* *}$ & $.128^{* *}$ & $-.069^{* *}$ & -.019 & $.157^{* *}$ & $.056^{* *}$ & $.158^{* *}$ \\
\hline & $\mathrm{N}$ & 32844 & 32844 & 32844 & 32844 & 32844 & 10147 & 10147 & 10147 & 10147 & 10147 \\
\hline
\end{tabular}

**. Correlation is significant at the 0.001 level (2-tailed). 


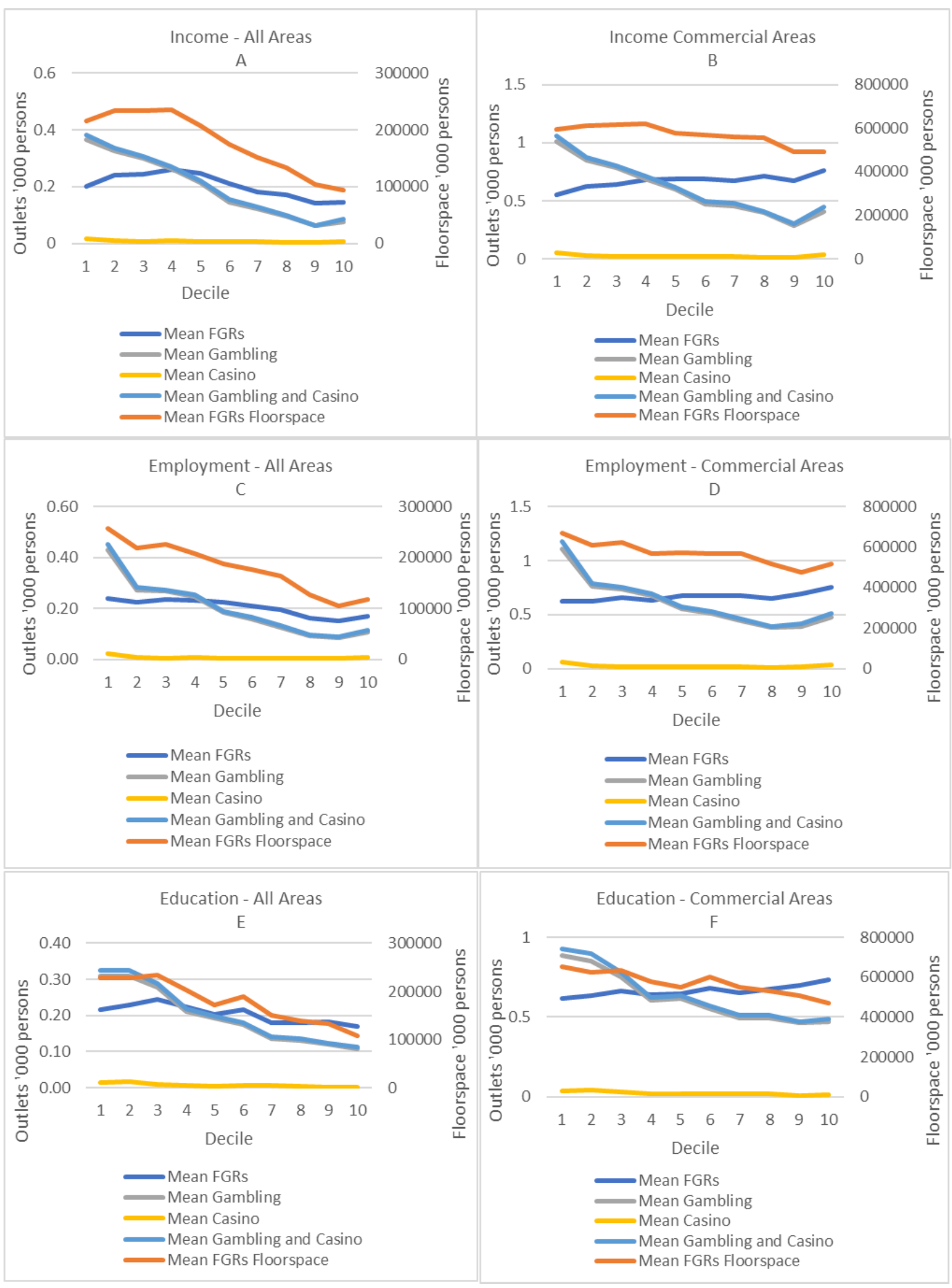

Figure 4 Mean distribution of food and grocery and gambling retailers' outlets ' 000 persons across income, employment and education deprivation deciles in England. 
Table 3 Multiple comparison test showing the mean differences for food, gambling and casino outlets ' 000 persons in decile 1 and 2 compared to other deciles for income deprivation domain

\begin{tabular}{|c|c|c|c|c|c|c|c|c|c|c|c|}
\hline & & \multicolumn{5}{|c|}{ All Areas } & \multicolumn{5}{|c|}{ Commercial Areas } \\
\hline & & $\begin{array}{c}\text { FGRs } \\
\text { outlets }\end{array}$ & $\begin{array}{c}\text { FGR } \\
\text { Floorspaces }\end{array}$ & $\begin{array}{c}\text { Gambling } \\
\text { outlets }\end{array}$ & Casinos & $\begin{array}{l}\text { Gambling } \\
\text { \& Casinos }\end{array}$ & $\begin{array}{l}\text { FGRs } \\
\text { Outlets }\end{array}$ & $\begin{array}{c}\text { FGR } \\
\text { Floorspace } \\
\text { s } \\
\end{array}$ & $\begin{array}{c}\text { Gambling } \\
\text { outlets }\end{array}$ & Casinos & $\begin{array}{l}\text { Gambling } \\
\text { \& Casinos }\end{array}$ \\
\hline $\begin{array}{l}\text { (I) } \\
\text { Inc. } \\
\text { Dec }\end{array}$ & $\begin{array}{l}\text { J) } \\
\text { Inc. } \\
\text { Dec } \\
\end{array}$ & & & & & Mean Diffe & ence $(\mathbf{I}-\mathbf{J})$ & & & & \\
\hline \multirow[t]{9}{*}{1} & 2 & $-.04112 *$ & -18274.42431 & .03967 & .00820 & .04786 & -.07645 & -14532.178 & .15925 & .02411 & .18337 \\
\hline & 3 & $-.04384 *$ & -18040.13670 & .06724 & $.01046^{*}$ & $.07770 *$ & $-.08932 *$ & -19472.554 & $.22400 *$ & $.02982 *$ & $.25382 * *$ \\
\hline & 4 & $-.05928 * *$ & -19758.13809 & $.10320 * *$ & .00912 & $.11232 * *$ & $-.13242 * *$ & -26286.192 & $.31593 * *$ & .02622 & $.34215 * *$ \\
\hline & 5 & $-.04696 *$ & 9033.44637 & $.15111 * *$ & $.01139 *$ & $.16250 * *$ & $-.13604 * *$ & 19413.470 & $.41097 * *$ & $.03122 *$ & $.44219 * *$ \\
\hline & 6 & -.01164 & 40767.94042 & $.21968 * *$ & .01033 & $.23002 * *$ & $-.13404 * *$ & 28077.410 & $.53554 * *$ & .02475 & $.56030 * *$ \\
\hline & 7 & .01811 & $63920.76618 * *$ & $.24184 * *$ & $.01222 *$ & $.25406^{* *}$ & $-.11906 * *$ & 35075.610 & $.55200 * *$ & .02824 & $.58023 * *$ \\
\hline & 8 & .02851 & $81852.71678 * *$ & $.27022 * *$ & $.01527 *$ & $.28549 * *$ & $-.16096 * *$ & 38498.466 & $.61206 * *$ & $.03817 *$ & $.65023 * *$ \\
\hline & 9 & $.05762 * *$ & $111493.36342 * *$ & $.30429 * *$ & $.01565^{*}$ & $.31994 * *$ & $-.11775 * *$ & 104629.735 & $.72015 * *$ & $.03841 *$ & $.75857 * *$ \\
\hline & 10 & $.05564 * *$ & $122297.18206 * *$ & $.28804 * *$ & $.01095^{*}$ & $.29899 * *$ & $-.20768 * *$ & 103123.081 & $.60058 * *$ & .01233 & $.61291 * *$ \\
\hline \multirow[t]{9}{*}{2} & 1 & $.04112 *$ & 18274.42431 & -.03967 & -.00820 & -.04786 & 0.07645 & 14532.178 & -0.15925 & -.02411 & -.18337 \\
\hline & 3 & -.00272 & 234.28761 & .02758 & .00226 & .02984 & -0.01287 & -4940.377 & 0.06475 & .00571 & .07045 \\
\hline & 4 & -.01816 & -1483.71378 & .06353 & .00092 & .06445 & -0.05597 & -11754.014 & $.15667 *$ & .00211 & .15878 \\
\hline & 5 & -.00584 & 27307.87068 & $.11144 * *$ & .00319 & $.11464 * *$ & -0.05958 & 33945.648 & $.25171 * *$ & .00711 & $.25882 * *$ \\
\hline & 6 & .02948 & $59042.36473 *$ & $.18002 * *$ & .00214 & $.18215^{* *}$ & -0.05758 & 42609.588 & $.37629 * *$ & .00064 & $.37693 * *$ \\
\hline & 7 & $.05924 * *$ & $82195.19049 * *$ & $.20217 * *$ & .00402 & $.20620 * *$ & -0.04261 & 49607.788 & $.39274 * *$ & .00412 & $.39686^{* *}$ \\
\hline & 8 & $.06963 * *$ & $100127.14109 * *$ & $.23055^{* *}$ & .00708 & $.23763 * *$ & -0.08451 & 53030.644 & $.45280 * *$ & .01406 & $.46686^{* *}$ \\
\hline & 9 & $.09874 * *$ & $129767.78773 * *$ & $.26462 * *$ & $.00746^{*}$ & $.27208 * *$ & -0.0413 & 119161.913 & $.56090 * *$ & .0143 & $.57520 * *$ \\
\hline & 10 & $.09676 * *$ & $140571.60637 * *$ & $.24837 * *$ & .00275 & $.25113 * *$ & -0.13122 & 117655.259 & $.44133 * *$ & -0.01178 & $.42955 * *$ \\
\hline
\end{tabular}

\footnotetext{
**The mean difference significant at .001 level

*The mean difference is significant at the .05 level

Decile $1=$ most deprived $10 \%$ LSOAs

Decile $10=$ least deprived 10\% LSOAs
} 
Table 4 Multiple comparison test showing the mean differences for food, gambling and casino outlets ' 000 persons in decile 1 and 2 compared to other deciles for employment deprivation domain

\begin{tabular}{|c|c|c|c|c|c|c|c|c|c|c|c|}
\hline & & \multicolumn{5}{|c|}{ All Areas } & \multicolumn{5}{|c|}{ Commercial Areas } \\
\hline & & $\begin{array}{c}\text { FGRs } \\
\text { outlets }\end{array}$ & $\begin{array}{c}\text { FGR } \\
\text { Floorspaces }\end{array}$ & $\begin{array}{c}\text { Gambling } \\
\text { outlets }\end{array}$ & Casinos & $\begin{array}{l}\text { Gambling } \\
\text { \& Casinos }\end{array}$ & $\begin{array}{c}\text { FGRs } \\
\text { outlets }\end{array}$ & $\begin{array}{c}\text { FGR } \\
\text { Floorspaces }\end{array}$ & $\begin{array}{c}\text { Gambling } \\
\text { outlets }\end{array}$ & Casinos & $\begin{array}{l}\text { Gambling } \\
\text { \& Casinos }\end{array}$ \\
\hline $\begin{array}{c}\text { (I) } \\
\text { Emp. } \\
\text { Dec } \\
\end{array}$ & $\begin{array}{c}(J) \\
\text { Emp. } \\
\text { Dec }\end{array}$ & \multicolumn{10}{|c|}{ Mean Difference (I -J) } \\
\hline 1 & 2 & .01617 & 39365.08064 & $.15647 * *$ & $.01497 * *$ & $.17144 * *$ & -.00240 & 58722.09388 & $.35169 * *$ & $.03689 *$ & $.38858 * *$ \\
\hline \multirow{17}{*}{2} & 3 & .00265 & 32787.17064 & $.16146^{* *}$ & $.01901 * *$ & $.18048 * *$ & -.03366 & 46518.20825 & $.37291 * *$ & $.04832 * *$ & $.42123 * *$ \\
\hline & 4 & .00768 & 49557.83742 & $.18174 * *$ & $.01737 * *$ & $.19911 * *$ & -.01315 & 98777.12172 & $.43594 * *$ & $.04398 *$ & $.47992 * *$ \\
\hline & 5 & .01598 & $69585.39985^{*}$ & $.24562 * *$ & $.01879 * *$ & $.26441 * *$ & -.05797 & 96737.46926 & $.55550 * *$ & $.04611 * *$ & $.60161 * *$ \\
\hline & 6 & .02986 & $81311.63580 * *$ & $.26829 * *$ & $.02015 * *$ & $.28843 * *$ & -.05436 & 99925.80672 & $.59494 * *$ & $.04942 * *$ & $.64436 * *$ \\
\hline & 7 & $.04536 *$ & $94993.82851 * *$ & $.30149 * *$ & $.01997 * *$ & $.32146 * *$ & -.05773 & 99342.50956 & $.66710 * *$ & $.04757 * *$ & $.71467 * *$ \\
\hline & 8 & $.07939 * *$ & $130655.45634 * *$ & $.33512 * *$ & $.02149 * *$ & $.35661 * *$ & -.03220 & $149872.72327 *$ & $.73035 * *$ & $.05104 * *$ & $.78139 * *$ \\
\hline & 9 & $.08716 * *$ & $153711.16816^{* *}$ & $.34196 * *$ & $.02048 * *$ & $.36244 * *$ & -.07561 & $192609.02059 * *$ & $.71576^{* *}$ & $.04489 *$ & $.76066 * *$ \\
\hline & 10 & $.06902 * *$ & $140358.17747 * *$ & $.32083 * *$ & $.01658 * *$ & $.33740 * *$ & $-.13046^{*}$ & $150891.20687^{*}$ & $.63686^{* *}$ & .02840 & $.66526 * *$ \\
\hline & 1 & -.01617 & -39365.08064 & $-.15647 * *$ & $-.01497 *$ & $-.17144^{* *}$ & .00240 & -58722.09388 & $-.35169 * *$ & $-.03689 *$ & $-.38858 * *$ \\
\hline & 3 & -.01353 & -6577.91000 & .00499 & .00404 & .00903 & -.03127 & -12203.88563 & .02122 & .01143 & .03265 \\
\hline & 4 & -.00849 & 10192.75678 & .02527 & .00240 & .02766 & -.01075 & 40055.02784 & .08425 & .00709 & .09134 \\
\hline & 5 & -.00019 & 30220.31921 & $.08915^{* *}$ & .00382 & $.09297 * *$ & -.05558 & 38015.37537 & $.20381 * *$ & .00922 & $.21303 * *$ \\
\hline & 6 & .01369 & 41946.55516 & $.11181 * *$ & .00518 & $.11699 * *$ & -.05197 & 41203.71284 & $.24325^{* *}$ & .01253 & $.25578 * *$ \\
\hline & 7 & .02919 & $55628.74787^{*}$ & $.14502 * *$ & .00500 & $.15002 * *$ & -.05534 & 40620.41568 & $.31541 * *$ & .01068 & $.32609 * *$ \\
\hline & 8 & $.06322 * *$ & $91290.37570 * *$ & $.17865^{* *}$ & $.00652 *$ & $.18517 * *$ & -.02980 & 91150.62939 & $.37866^{* *}$ & .01415 & $.39282 * *$ \\
\hline & 9 & $.07098 * *$ & $114346.08752 * *$ & $.18549 * *$ & .00551 & $.19100 * *$ & -.07322 & $133886.92670 *$ & $.36408 * *$ & .00800 & $.37208^{*}$ \\
\hline & 10 & $.05284 *$ & $100993.09683 * *$ & $.16436^{* *}$ & .00161 & $.16596 * *$ & $-.12806^{*}$ & 92169.11299 & $.28517 * *$ & -.00849 & $.27668 *$ \\
\hline
\end{tabular}

**The mean difference significant at .001 level

*The mean difference is significant at the .05 level.

Decile $1=$ most deprived 10\% LSOAs.

Decile $10=$ least deprived $10 \%$ LSOAs. 
Table 5 Multiple comparison test showing the mean differences for food, gambling and casino outlets ' 000 persons in decile 1 and 2 compared to other deciles for education deprivation domain

\begin{tabular}{|c|c|c|c|c|c|c|c|c|c|c|c|}
\hline & & \multicolumn{5}{|c|}{ All Areas } & \multicolumn{5}{|c|}{ Commercial Areas } \\
\hline & & $\begin{array}{l}\text { FGRs } \\
\text { outlets }\end{array}$ & $\begin{array}{l}\text { FGR } \\
\text { Floorspaces }\end{array}$ & $\begin{array}{l}\text { Gambling } \\
\text { outlets }\end{array}$ & Casinos & $\begin{array}{l}\text { Gambling } \\
\text { \& Casino }\end{array}$ & $\begin{array}{l}\text { FGRs } \\
\text { outlets }\end{array}$ & $\begin{array}{l}\text { FGR } \\
\text { Floorspaces }\end{array}$ & $\begin{array}{l}\text { Gambling } \\
\text { outlets }\end{array}$ & Casinos & $\begin{array}{l}\text { Gambling } \\
\text { \& Casinos } \\
\end{array}$ \\
\hline $\begin{array}{l}\text { (I) } \\
\text { Edu. } \\
\text { Dec } \\
\end{array}$ & $\begin{array}{l}\text { (J) } \\
\text { Edu. } \\
\text { Dec } \\
\end{array}$ & \multicolumn{10}{|c|}{ Mean Difference $(\mathbf{I}-J)$} \\
\hline \multirow[t]{9}{*}{1} & 2 & -.01384 & 1328.17369 & .00038 & -.00228 & -.00190 & -.01322 & 30011.03295 & .03680 & -.00469 & .03212 \\
\hline & 3 & -.02939 & -6074.52035 & .03266 & .00311 & .03577 & -.04618 & 19032.86348 & .13678 & .01058 & .14736 \\
\hline & 4 & -.00920 & 25454.19823 & $.09854 * *$ & .00616 & $.10469 * *$ & -.02413 & 75031.94690 & $.28472 * *$ & .01774 & $.30246 * *$ \\
\hline & 5 & .01326 & $56790.01844^{*}$ & $.11646^{* *}$ & .00815 & $.12461 * *$ & -.02952 & 105631.83030 & $.26950 * *$ & .02150 & $.29100 * *$ \\
\hline & 6 & .00002 & 38659.86031 & $.13583 * *$ & .00775 & $.14359 * *$ & -.06436 & 54209.97244 & $.33761 * *$ & .02043 & $.35804 * *$ \\
\hline & 7 & $.03555^{*}$ & $77444.03467 * *$ & $.17442 * *$ & .00785 & $.18227 * *$ & -.03507 & 107313.82346 & $.39726 * *$ & .01798 & $.41524 * *$ \\
\hline & 8 & $.03672 *$ & $88537.99382 * *$ & $.17996 * *$ & .00824 & $.18820 * *$ & -.05874 & $125778.36093 *$ & $.39713 * *$ & .01851 & $.41564 * *$ \\
\hline & 9 & .03259 & $95444.16607 * *$ & $.18902 * *$ & $.01104 *$ & $.20006 * *$ & -.08303 & $145612.60424 *$ & $.42568 * *$ & $.02898 *$ & $.45467 * *$ \\
\hline & 10 & $.04693 *$ & $119686.01747 * *$ & $.20106^{* *}$ & $.01073 *$ & $.21180 * *$ & -.11472 & $182716.28989 * *$ & $.41599 * *$ & $.02624 *$ & $.44223 * *$ \\
\hline \multirow[t]{9}{*}{2} & 1 & .01384 & -1328.17369 & -.00038 & .00228 & .00190 & .01322 & -30011.03295 & -.03680 & .00469 & -.03212 \\
\hline & 3 & -.01555 & -7402.69403 & .03228 & .00539 & .03767 & -.03297 & -10978.16947 & .09997 & .01527 & .11525 \\
\hline & 4 & .00465 & 24126.02454 & $.09815 * *$ & .00844 & $.10660 * *$ & -.01091 & 45020.91394 & $.24792 * *$ & .02243 & $.27035 * *$ \\
\hline & 5 & .02710 & $55461.84475^{*}$ & $.11608 * *$ & $.01044 *$ & $.12651 * *$ & -.01631 & 75620.79735 & $.23270 *$ & .02618 & $.25888 * *$ \\
\hline & 6 & .01387 & 37331.68662 & $.13545 * *$ & .01004 & $.14549 * *$ & -.05114 & 24198.93949 & $.30081 * *$ & .02512 & $.32593 * *$ \\
\hline & 7 & $.04940 * *$ & $76115.86098 * *$ & $.17404 * *$ & .01013 & $.18417 * *$ & -.02185 & 77302.79051 & $.36045 * *$ & .02267 & $.38312 * *$ \\
\hline & 8 & $.05056 * *$ & $87209.82014 * *$ & $.17958 * *$ & .01052 & $.19010 * *$ & -.04552 & 95767.32798 & $.36032 * *$ & .02320 & $.38352 * *$ \\
\hline & 9 & $.04644 *$ & $94115.99238 * *$ & $.18864 * *$ & $.01332 *$ & $.20196 * *$ & -.06982 & 115601.57129 & $.38888 * *$ & $.03367 *$ & $.42255^{* *}$ \\
\hline & 10 & $.06078 * *$ & $118357.84379 * *$ & $.20068 * *$ & $.01302 *$ & $.21370 * *$ & -.10150 & $152705.25694 *$ & $.37919 * *$ & $.03093 *$ & $.41012 * *$ \\
\hline
\end{tabular}

**The mean difference significant at .001 level

*The mean difference is significant at the .05 level.

Decile $1=$ most deprived $10 \%$ LSOAs.

Decile $10=$ least deprived $10 \%$ LSOAs. 
Table 6 Binomial logistic regression results (odds ratio) for income, employment and education deprivation and presence or absence of FGR floorspace, gambling and casino outlets.

\begin{tabular}{|c|c|c|c|c|c|c|c|c|}
\hline \multicolumn{5}{|c|}{ All Areas } & \multicolumn{4}{|c|}{ Commercial Areas } \\
\hline Decile & $\begin{array}{c}\text { FGR } \\
\text { Floorspaces }\end{array}$ & $\begin{array}{c}\text { Gambling } \\
\text { outlets }\end{array}$ & Casinos & $\begin{array}{l}\text { Gambling } \\
\text { \& Casino }\end{array}$ & $\begin{array}{c}\text { FGR } \\
\text { Floorspaces }\end{array}$ & $\begin{array}{c}\text { Gambling } \\
\text { outlets }\end{array}$ & Casinos & $\begin{array}{c}\text { Gambling } \\
\& \\
\text { Casinos } \\
\end{array}$ \\
\hline \multicolumn{9}{|c|}{ Income Deprivation } \\
\hline Inc. Dec (1) & $1.320^{* *}$ & $5.893^{* *}$ & $2.427^{* *}$ & $5.738^{* *}$ & $.174 * *$ & $6.319^{* *}$ & 1.273 & $6.246^{* *}$ \\
\hline Inc. Dec (2) & $1.725^{* *}$ & $5.702 * *$ & 1.445 & $5.502 * *$ & $.260 * *$ & $4.785^{* *}$ & .705 & $4.591 * *$ \\
\hline Inc. Dec (3) & $1.849^{* *}$ & $5.172 * *$ & 1.404 & $5.001^{* *}$ & $.318^{* *}$ & $3.970^{* *}$ & .691 & $3.819^{* *}$ \\
\hline Inc. Dec (4) & $1.974^{* *}$ & $4.655^{* *}$ & 1.243 & $4.495^{* *}$ & $.386^{* *}$ & $3.253^{* *}$ & .613 & $3.116^{* *}$ \\
\hline Inc. Dec (5) & $1.959^{* *}$ & $3.950^{* *}$ & .960 & $3.811^{* *}$ & $.479 * *$ & $2.730^{* *}$ & $.498^{*}$ & $2.607^{* *}$ \\
\hline Inc. Dec (6) & $1.663 * *$ & $2.726^{* *}$ & 1.243 & $2.661^{* *}$ & $.564 * *$ & $1.987 * *$ & .757 & $1.932 * *$ \\
\hline Inc. Dec (7) & $1.403^{* *}$ & $2.337^{* *}$ & .799 & $2.293^{* *}$ & $.563 * *$ & $1.972 * *$ & .551 & $1.935^{* *}$ \\
\hline Inc. Dec (8) & $1.281^{* *}$ & $1.658^{* *}$ & .518 & $1.622 * *$ & .760 & $1.426^{*}$ & .401 & $1.387^{*}$ \\
\hline Inc. Dec (9) & 1.122 & 1.140 & $.438^{*}$ & 1.108 & .862 & 1.016 & .384 & .977 \\
\hline Constant & .204 & .062 & .008 & .064 & 8.058 & .440 & .042 & .467 \\
\hline \multicolumn{9}{|c|}{ Employment Deprivation } \\
\hline Emp. Dec (1) & $1.266^{* *}$ & $4.244^{* *}$ & $2.709^{* *}$ & $4.179^{* *}$ & $.241 * *$ & $4.582 * *$ & $1.609^{*}$ & $4.590^{* *}$ \\
\hline Emp. Dec (2) & $1.343^{* *}$ & $3.294^{* *}$ & 1.338 & $3.220 * *$ & $.340 * *$ & $3.155^{* *}$ & .840 & $3.077^{* *}$ \\
\hline Emp. Dec (3) & $1.445^{* *}$ & $3.084^{* *}$ & .765 & $2.989^{* *}$ & $.397^{* *}$ & $2.672 * *$ & $.471^{*}$ & $2.556^{* *}$ \\
\hline Emp. Dec (4) & $1.490^{* *}$ & $3.063^{* *}$ & .899 & $2.974^{* *}$ & $.415^{* *}$ & $2.567^{* *}$ & $.549^{*}$ & $2.465^{* *}$ \\
\hline Emp. Dec (5) & $1.439 * *$ & $2.248^{* *}$ & .732 & $2.203^{* *}$ & $.579 * *$ & $1.843^{* *}$ & $.495^{*}$ & $1.797 * *$ \\
\hline Emp. Dec (6) & $1.345^{* *}$ & $1.912^{* *}$ & .665 & $1.878^{* *}$ & $.605^{* *}$ & $1.578^{* *}$ & $.477^{*}$ & $1.541^{* *}$ \\
\hline Emp. Dec (7) & $1.278^{* *}$ & $1.511^{* *}$ & $.531^{*}$ & $1.485^{* *}$ & .766 & $1.262^{*}$ & $.413^{*}$ & $1.230^{*}$ \\
\hline Emp. Dec (8) & 1.045 & $1.228^{*}$ & $.498^{*}$ & $1.205^{*}$ & $.752 *$ & 1.197 & $.453^{*}$ & 1.166 \\
\hline Emp. Dec (9) & .953 & .950 & $.431^{*}$ & .940 & .981 & .983 & $.439^{*}$ & .968 \\
\hline Constant & .246 & .093 & .009 & .096 & 6.612 & .597 & .042 & .629 \\
\hline \multicolumn{9}{|c|}{ Education Deprivation } \\
\hline Edu. Dec (1) & $1.239^{* *}$ & $2.675^{* *}$ & $3.165^{* *}$ & $2.672^{* *}$ & $.360^{* *}$ & $2.549^{* *}$ & $2.115^{*}$ & $2.566^{* *}$ \\
\hline Edu. Dec (2) & $1.381^{* *}$ & $2.689^{* *}$ & $3.507^{* *}$ & $2.685^{* *}$ & $.409^{* *}$ & $2.284^{* *}$ & $2.251^{*}$ & $2.295^{* *}$ \\
\hline Edu. Dec (3) & $1.566^{* *}$ & $2.352 * *$ & $2.823^{* *}$ & $2.343^{* *}$ & $.538^{* *}$ & $1.683^{* *}$ & 1.775 & $1.675^{* *}$ \\
\hline Edu. Dec (4) & $1.475^{* *}$ & $2.110^{* *}$ & $2.145^{*}$ & $2.128^{* *}$ & $.556^{* *}$ & $1.555^{* *}$ & 1.415 & $1.582 * *$ \\
\hline Edu. Dec (5) & $1.305^{* *}$ & $1.776^{* *}$ & 1.672 & $1.780^{* *}$ & $.608^{* *}$ & $1.463^{* *}$ & 1.234 & $1.472 * *$ \\
\hline Edu. Dec (6) & $1.426^{* *}$ & $1.625^{* *}$ & 1.538 & $1.630^{* *}$ & $.792 * *$ & $1.225^{*}$ & 1.121 & $1.232 *$ \\
\hline Edu. Dec (7) & $1.165^{*}$ & $1.352^{* *}$ & 1.403 & $1.356^{* *}$ & $.722 *$ & 1.175 & 1.174 & 1.181 \\
\hline Edu. Dec (8) & $1.140^{*}$ & $1.188^{*}$ & 1.201 & $1.193^{*}$ & .820 & 1.028 & 1.046 & 1.035 \\
\hline Edu. Dec (9) & $1.161^{*}$ & 1.121 & .733 & 1.123 & .957 & .958 & .642 & .960 \\
\hline Constant & .241 & .115 & .005 & .116 & 5.353 & .809 & .020 & .826 \\
\hline
\end{tabular}

Odds ratio significant at $* \mathrm{P}<.05, * * \mathrm{P}<.001$

Decile $1=$ most deprived $10 \%$ LSOAs.

Decile $10=$ least deprived $10 \%$ LSOAs. 